\title{
Assessing visitor satisfaction with tourism rejuvenation policies: the case of Rimini, Italy ${ }^{*}$
}

\author{
RINALDO BRAU \\ Department of Economics and CRENoS, University of Cagliari, Italy \\ ANTONELLO E. SCORCU \\ University of Bologna and $\mathrm{RCE} A$, Italy \\ LAURA VICI \\ University of Bologna, Italy
}

\begin{abstract}
In this paper we assess the appeal of potential interventions on the tourism offer of Rimini, a popular Italian seaside holiday destination, by means of a choice modelling analysis. Tourism can be viewed as a composite good, its overall utility depending on the arrangement of the component characteristics. Our discrete choice experiments incorporate as attributes a number of possible changes to current tourist activities (the subject of public debate), including them in hypothetical alternative holiday packages. The conditional logit analysis indicates that tourists show lesser preference for interventions aimed at protecting the environmental integrity of the beach and greater preference for those, such as the creation of a pedestrianised seafront with late-night opening of amenities and facilities, that are likely to diminish the role of the traditional sea, sun and sand component of the overall holiday experience.
\end{abstract}

\footnotetext{
* This research was funded by the PRIN (National Interest Programme Research) project "Sustainable local development and tourism". We wish to thank Guido Candela, Massimiliano Castellani, Paolo Figini, Maurizio Mussoni, Tiziana Troia, and all participants in the above project. Useful insights were provided by participants in the XVIII Siep conference, Pavia 14-15 September 2006; Economics of Tourism Workshop, Rimini 20 April 2007.

** This version: September, 2007.
} 


\section{Introduction}

Tourism services evolve continuously as processes and tourism businesses have to adjust to changing demand.

Generally speaking, "tourism" indicates a composite and heterogeneous good demanded by different classes of individuals, whose needs and perceptions may differ substantially. For some people, tourism is mainly perceived as time devoted to leisure activities, for others it provides an opportunity to meet people, take part in unusual activities, visit new places, friends and relatives, etc. Accordingly, each tourist destination, with its unique natural and built resources, attractions and policies, is more suited to a particular kind of tourist than to others. Nonetheless, the same destination may not necessarily cater simply to niche markets but can host several categories of tourists in the same season.

For this reason, destinations should identify what type of tourists are better served and which segment of potential tourists could be optimally targeted, so as to enhance the ability to maximize their main goals in terms of arrivals and profits. Moreover, to increase their competitiveness in tourism markets, destinations usually diversify their product and launch new attractions, providing tourists with ever larger choice sets among which to choose what best satisfies their preferences.

These developments require flexible and well-planned tourist policies, able to capture future changes. In this respect, the analysis of tourism characteristics, market perspectives and tourism policies is attractive to local communities and policymakers for three reasons. First, understanding the evolution in tourists' needs enables destinations to improve supply. Second, a knowledge of the relative importance of the key features characterizing local tourist goods improves the effectiveness of tourism policies. Third, information on tourist and local community preferences is an important component of sustainable development and may enhance economic growth. ${ }^{1}$

All this can be expressed in a series of simple questions. First, does the current supply for a given destination fully satisfy demand or is there some mismatch as a result of a distorted perception by the local stakeholders? What kind of characteristics of tourism services and available infrastructures can make a destination more attractive for tourists? In the event some specific projects have been identified as the preferred candidate for implementing a tourism revitalization policy, which alternative projects best satisfy the different types of tourists hosted in that area? Clearly, if a given combination of characteristics maximizes the utility that a holiday package can provide to a particular type of tourist, more effective targeting policies could be developed.

In this paper we aim to answer this kind of question for the case of Rimini, a mass-tourist destination, by making use of discrete choice modeling methods. The theoretical framework

\footnotetext{
${ }^{1}$ In a related paper, Figini et al. (2007) consider resident preferences and social improving policies.
} 
adopted models tourism as a dynamic, composite, complex and heterogeneous good, and tourist preferences accordingly.

The second contribution of this study to the literature is the assessment of whether (and to what extent) choice experiment techniques can be used for evaluating large-scale urban planning projects aimed at revitalizing the appeal of "mature" tourist areas.

Choice modeling is increasingly used in tourism economics and applications include the analysis of destination choices on the basis of location and trip attributes (Huybers and Bennett, 2000; Huybers, 2005; Papatheodorou, 2001; Crouch and Louviere, 2004), recreation demand (Breffle and Morey, 2000) and demand for heritage attractions; Morey et al. 2002; Apostolakis et al., 2005). A few contributions, though not directly dealing with tourism issues, are related to the present study since they use choice modeling techniques for evaluating public support to alternative urban redevelopment plans in tourist towns (Alberini et al., 2005a; 2005b). Likewise, in our survey, respondents are faced with choice sets of hypothetical alternative tourist packages, defined by six attributes, which describe new models of town development, with different cultural offers, environment policies and urban and tourism planning regulations.

Using discrete choice modelling methods it is possible to estimate the probability of choosing destinations as a function of key attributes and levels, which equates to estimating the market share of different locations having different characteristics. ${ }^{2}$ In order to test some theoretical conjectures about tourist behavior and analyze the attractiveness of alternative policy plans, the estimated parameters of related econometric models provide the relative weight (and a monetary evaluation) of each attribute affecting tourist choice.

The remainder of the paper is organized as follows. Section 2 provides some background information on Rimini, its tourist flows and policies. It also describes the structure and administration of the survey, and the discrete choice questions. Section 3 presents the theoretical and econometric models and the data. Section 4 illustrates the results and some policy implications and the conclusions are presented in section 5 .

\section{Evaluating changes to Rimini's tourism offer}

\subsection{Background}

Rimini is a mature mass-tourism destination ${ }^{3}$ which for many years has strived to satisfy all the needs of its tourists, disregarding their heterogeneity and the dynamic nature of

\footnotetext{
${ }^{2}$ For a recent application, see Crouch et al. (2007).

${ }^{3}$ In summer, tourists are attracted by its extensive beaches and cheap rates. Every year, from May to September, Rimini hosts an average 1.9 million tourists in terms of arrivals with over 12.7 million overnight stays (Source: Bureau of Statistics of the Province of Rimini).
} 
tourism and tourist preferences. Consequently, very few novelties have been introduced over the last few years, the tourist product remaining practically unchanged.

Unsurprisingly, the ability of Rimini to attract tourists has dwindled, both in relative and absolute terms, resulting in a decrease in overnight stays in spite of a slight positive trend in the number of arrivals.

The reduction in average length of stay is particularly marked in Rimini, but reflects the general trend. The world of work has changed, annual leave has increased and long holidays are being replaced by shorter, more frequent breaks throughout the year. Moreover, transportation costs have decreased and access to detailed information on tourist services and destinations has become easier.

A shorter average stay produces negative externalities in terms of road traffic congestion and air pollution, which negatively affect the tourism experience. Worse still, the demand for weekend stays leads to an increase in accommodation capacity, but reduces the average use of tourist infrastructures.

The interaction of these phenomena necessitates a redefinition of Rimini's tourism services with a view to maintaining and possibly recovering its market position. Policy makers and tourism businesses need to reconsider the tourism product currently offered by this destination, ascertain tourist preferences and predict their behaviour, in order to assess whether they are still able to fully satisfy tourist demand, or whether there is some mismatch as a result of distorted perception by local stakeholders. This is not an easy task as a large proportion of tourists in Rimini does not buy all-inclusive tourist packages with a predetermined and fixed set of services, but organizes their own trip. ${ }^{4}$

On the basis of the above considerations, this study is aimed at indirectly answering two main questions. First, what potential alternatives can be offered to experienced tourists to encourage them to stay longer in Rimini? Second, what kind of characteristics make Rimini attractive and for what types of tourist?

\subsection{Choice experiment design}

To answer the above questions, we surveyed a sample of 'experienced tourists' in Rimini. ${ }^{5}$ Tourists were contacted on the beach, in the town's pubs, shops and hotels in summer 2005, and their preferences elicited by means of the choice modelling method, namely the choice experiments technique (CE).

\footnotetext{
${ }^{4}$ Eighty-three per cent of tourists in Rimini (52\% of foreign and $91 \%$ of Italian tourists) organize their own holidays, without going through tour operators or travel agencies (Scorcu and Vici, 2006). The destination offers a wide array of services to be purchased either by private visitors or tour operators, leaving ample room for product differentiation strategies.

${ }^{5}$ More precisely, our experienced tourists are those who recently spent their summer holidays in Rimini. The sample is therefore representative of the typical Rimini tourist, but not of potential new categories of tourists to that destination.
} 
In CE respondents are asked to choose among alternative goods, defined in terms of a series of constituent attributes. The alternatives differ in the (systematic) combinations of different attribute levels. The resultant sequence of choices enables to model the choice probability of any alternative as a function of the attributes considered. In turn, this provides precise information on the respondents' willingness to trade-off among different attributes.

For the design of our CE, the first step consisted in defining the good to be evaluated in terms of its attributes and related levels. To achieve the objective, the selected attributes need to be key factors in the decision to continue spending a holiday in Rimini. Our choice was partly dictated by factors suggested in the literature (e.g. overcrowding), and largely influenced by the on-going public debate about the main interventions that could rejuvenate the towns' appeal. The main difficulty was to develop scenarios able to account for the complexity of Rimini's offer, which combines "sea and sunshine" with historical and recreational aspects. Frequent research meetings and a pilot test carried out in the first two weeks of July 2005 showed the attributes to be comprehensible, clearly presented and, above all, taken into account by tourists in their choices. ${ }^{6}$

The CE question asked respondents to choose their preferred option from among sets of hypothetical alternative arrangements of the tourist area. In order to constrain respondents' answers within the structured format of CE studies, tourists were asked to imagine spending a week in Rimini for a seaside vacation with accommodation in a three-star hotel near the beach. Given this common scenario, respondents were asked to state their preference between two hypothetical alternative holidays, A and B, where each scenario was described by the six attributes and their levels described in Table 1 . The attributes considered are: aversion to overcrowding at the seaside resort, the use of the promenade as a pedestrian area, the degree of environmental impact on the beach, the combination of sea-only holiday with cultural packages, the possibility of using the beach for late-night events, and the accommodation cost per night per person in a three star hotel. All the resulting scenarios presented to respondents could be judged realistic and realizable with suitable policies and limited public investment.

Expectations on the effects of the considered attributes on tourist utility are mixed. For example, we expect tourists to be environmentally aware, especially as far as beach preservation is concerned, the key attraction of a seaside resort. By contrast, given the prevailing kind of tourism in this destination, we infer that cultural products are not of interest to most tourists.

Concerning the risk of overcrowding, we have no a priori expectation as to the sign of this attribute. On the one hand it is well-known that some tourists in Rimini like crowded places. On the other, traffic congestion reduces space and increases trip times to reach the main ${ }^{6}$ If respondents view the process as entirely hypothetical or useless, then their responses will not be
meaningful in any economic sense (Carson 2000). 
attractions. However, we expect pedestrianisation of the seafront to increase open spaces for tourists and positively affect the attractiveness of the scenario.

\subsection{Questionnaire structure and administration}

The questionnaire designed for the survey and available in Italian, English and German, comprised four sections. The first section concerned respondents' socio-economic and demographic characteristics, namely gender, age, place and Italian region or country of origin, nationality, education, occupation. The second section included questions on the tourists' holiday, namely form of booking (e.g. through a tour operator or organized on their own), transportation used, type of accommodation and other information about the reasons for having chosen to spend a holiday in Rimini.

In the third section eight choice experiments were presented for each respondent. After a brief introduction, explaining the main reasons for the survey, respondents were asked to imagine spending a week's holiday in a three-star hotel (a typical seaside vacation with accommodation near the beach) in Rimini.

In order to provide a clear, uniform understanding of the attributes and to facilitate the individual decision process, the verbal explanation was accompanied by drawings and photos representing each attribute level. The respondent was then asked to choose his or her preferred alternative within choice sets comprising two hypothetical alternatives (labeled Holiday A and Holiday B) consisting of different levels of the six attributes described above. ${ }^{8}$ A shifted design strategy was used to create pair-wise comparisons (Louviere et al., 2000). In order to train the respondent, he/she was shown an example of the card like the one in Figure 1, before being presented with the actual choice experiment cards.

Interviews were split into four groups, each consisting of 8 choice sets. In every group, the cards submitted were the same but presented each time in a different sequence, so as to avoid any order bias. 9 An orthogonal fractional factorial design was used to reduce the number of profiles to a convenient size (32 alternatives out of a full factorial of 512 possible profiles) and, at the same time, to help maintain reliable results.

The last section of the questionnaire contained a few questions to enable the interviewer to assess the reliability of answers, namely the degree of comprehension, interest and ease in answering the questions and choosing the alternatives. In general, the questionnaire was well received and few problems of poor identification of alternative scenarios arose were not relevant.

\footnotetext{
7 The aim of these questions was to determine the size of different relevant market tourism segments typically considered to visit this destination.

8 We did not explicitly consider a "status quo" alternative, though it is implicitly defined (and can be identified) in terms of a specific set of attribute levels provided in the questionnaire.

${ }^{9}$ We checked whether any respondents always selected the option on the left or on the right as their answers to all choice questions. We found that one individual out of 605 picked the Holiday A option in all choice questions, whereas another two respondents always chose the Holiday B alternative.
} 


\section{Table 1: Definition of attributes and their levels}

\begin{tabular}{|c|c|}
\hline 1. & $\begin{array}{l}\text { Risk of overcrowding in seaside resorts (making it less easy to move around): } \\
\text { - High risk: Overcrowding does not allow easy access or movement within the } \\
\text { destination for reaching recreational facilities (for ex. cinema, theaters, discos etc....) } \\
\text { or nearby destinations (by the coast or in the hinterland). }\end{array}$ \\
\hline & $\begin{array}{l}\text { - Low risk: The seaside resort provides easy access and movement within the } \\
\text { destination for reaching recreational facilities (for ex. cinema, theaters, discos etc....) } \\
\text { or nearby destinations (by the coast or in the hinterland). }\end{array}$ \\
\hline \multirow[t]{3}{*}{2.} & The main attraction of a seaside resort is the seafront \\
\hline & $\begin{array}{l}\text { - The seafront is a pedestrian area (promenade) with extensive open spaces for } \\
\text { pedestrians and cyclists; no access to motor vehicles, parking outside the area; } \\
\text { infrastructure designed as leisure and recreational amenity. }\end{array}$ \\
\hline & $\begin{array}{l}\text { - Vehicle access permitted along seafront: few open spaces; cyclists use sidewalk; } \\
\text { parking spaces close to the beach and no traffic restrictions. }\end{array}$ \\
\hline \multirow[t]{5}{*}{3.} & An uncontaminated beach: \\
\hline & - $\quad$ Minimal impact: No beach services and facilities. \\
\hline & $\begin{array}{l}\text { - Medium impact: Essential beach services and facilities (lifeguard, first aid, } \\
\text { information, refreshments, etc...) are provided in permanent premises. }\end{array}$ \\
\hline & $\begin{array}{l}\text { - Temporary high impact: Several beach services and amenities are provided in } \\
\text { temporary premises dismantled in winter. }\end{array}$ \\
\hline & $\begin{array}{l}\text { - Permanent high impact: Several buildings on the beach and wide supply of } \\
\text { services and amenities. All premises permanent. }\end{array}$ \\
\hline \multirow[t]{5}{*}{4.} & Combination of sea and culture (Rimini as a city of Arts and of Museums): \\
\hline & - Sea: Seaside holiday only. \\
\hline & - Sea and monuments: Seaside holiday with guided tour of city's cultural heritage. \\
\hline & $\begin{array}{l}\text { - Sea, monuments and Museums 1: Seaside holiday, guided tour of city's heritage and } \\
\text { entrance to the city's Museum (guided tour in the evening). }\end{array}$ \\
\hline & $\begin{array}{l}\text { - Sea, monuments and Museums 2: Seaside holiday, guided tour of city's heritage and } \\
\text { entrance to the Diniz Rialto ethnic museum (guided tour in the evening). }\end{array}$ \\
\hline \multirow[t]{3}{*}{5.} & Late night access to the beach: \\
\hline & $\begin{array}{l}\text { - Closed beach: evening-night closing of the beach. The public beach is accessible } \\
\text { with restrictions. }\end{array}$ \\
\hline & - Open beach: evening-night opening of the beach to host events. \\
\hline & $\begin{array}{l}\text { Daily cost per person per night (full board accommodation in double room in a three } \\
\text { star hotel). The various possible holiday options to choose from are priced as follows } \\
\text { (price per room in brackets): }\end{array}$ \\
\hline & $-30(60)$ Euro \\
\hline & - $40(80)$ Euro \\
\hline & - $50(100)$ Euro \\
\hline & - $60(120)$ Euro \\
\hline
\end{tabular}

A total of 605 respondents concluded the survey. Interviews were carried out in person by two professionally trained interviewers between July and August 2005. The reported level of comprehension of the questions was high $(92 \%$ of the sample understood the questionnaire) and perception of the differences in scenarios was quite evident $(80 \%$ of the sample had no problems in distinguishing between alternatives). Interviews took on average 15 minutes. 
The sample plan relied on a priori information drawn from an earlier study on tourists' behaviour in Rimini and on official data for overnight stays in this destination. ${ }^{10}$ The sample design established $20 \%$ of interviews with foreign tourists and $80 \%$ with tourists coming from 20 Italian regions. Genders were equally represented in the sample.

Interviews were conducted in different places, so as to collect information from tourists whose main reasons for spending holidays in Rimini might differ. In particular, out of the 605 interviewees, 296 respondents were contacted on the beach during the day (a maximum of 3 interviews per beach front concession), 155 in three-star hotels (a maximum of 5 interviews per hotel, avoiding contacting people staying in hotels nearby the beaches already covered), 102 in pubs. The remaining 52 interviews were carried out in the historical city centre.

Figure 1: Example of card used in choice experiments

\begin{tabular}{|l|c|c|}
\hline Features of the holiday & Holiday A & Holiday B \\
\hline $\begin{array}{l}\text { Risk of overcrowding in main point of } \\
\text { attraction }\end{array}$ & High & Low \\
\hline Quality of seafront & $\begin{array}{c}\text { Seafront for } \\
\text { pedestrians only }\end{array}$ & $\begin{array}{c}\text { Vehicle access } \\
\text { to seafront }\end{array}$ \\
\hline $\begin{array}{l}\text { Uncontaminated and untouched natural } \\
\text { environment as a primary attraction }\end{array}$ & Minimal impact & $\begin{array}{c}\text { Permanent high } \\
\text { impact }\end{array}$ \\
\hline Combination of beach and cultural holiday & Sea & $\begin{array}{c}\text { Sea, monuments } \\
\text { and museums 2 }\end{array}$ \\
\hline Late-night opening of the beach & Beach closed & Beach open \\
\hline Price per person per night & 30 & 60 \\
\hline Preferences & $\square$ & $\square$ \\
\hline
\end{tabular}

\section{Econometric framework and empirical model}

\subsection{The model}

The choice modeling method is a stated-preference approach since it studies individual behaviour and estimates the value of the goods by asking people to state their preferences within a hypothetical framework. One of the main advantages of this method is the possibility of evaluating policy interventions where no market exists.

${ }^{10}$ See ISTAT (2005). 
The theoretical foundations of discrete choice modelling are the characteristics approach to demand analysis (Lancaster, 1966, 1971), since preferences are elicited as a function of component attributes, and the random utility theory (Thurstone, 1927), which constitutes the basis for limited dependent variable models.

According to the random utility theory, the choice made by respondents identifies the combination of attribute levels which maximizes their utility across alternatives, for a given choice set. Formally, given a sample of $H$ individuals, with $b=1,2, \ldots \ldots . H$ and a set of alternative choices, $j=1, \ldots . J$, the utility that individual $h$ derives from choosing alternative $j$ out of $J$ can be represented as follows:

$$
U_{b j}=\beta^{\prime} \mathbf{x}_{b j}+\varepsilon_{b j} .
$$

The above expression is a conditional indirect utility function for the choice alternative $j$ made by consumer $h$ and is composed of a linear deterministic component and a random term, $\varepsilon_{b j}$.

Standard empirical analyses are based on the discrete choice conditional logit model. This model assumes that the error terms $\varepsilon$ are independently and identically distributed (IID) according to a Gumbel (extreme value type 1) distribution, thus providing the following closed form for the probability that individual $b$ selects alternative $i$ out of $C_{b}$ alternatives:

$$
P\left[y_{h}=i\right]=\frac{\exp \left(\beta^{\prime} x_{i}^{h}\right)}{\sum_{j=1}^{J} \exp \left(\beta^{\prime} x_{j}^{h}\right)},
$$

where $y_{b}$ is a choice index which represents the choice made by individual $h$.

For any individual $h$, expression [2] defines the probability that the sum of the systematic and random utility terms of option $i$ is greater than the corresponding term for any other option $j$ in the choice set $C_{b}$

The IID assumption across alternatives for the es entails the property of independence of irrelevant alternative (IIA), which means that the relative probability of choosing one alternative over another is independent of the availability of additional attributes or alternatives. Broadly speaking, once a choice has to be made between two alternatives, the decision does not depend on the existence of other alternatives (McFadden, 1984). ${ }^{11}$ Therefore, if some alternatives, for practical reasons, are excluded from the choice set, the parameter estimates are still consistent (Train, 2003).

Once the model is fitted, the estimated $\beta$ coefficients of equation [2] determine the rate at which respondents are willing to trade-off one attribute of their holiday for another:

11 Violations of the IIA assumption may arise when some alternatives are qualitatively similar to others or there are heterogeneous preferences among respondents. If IIA is violated, alternative choice models should be used, such as the nested logit model, the random-coefficient logit model or the multinomial probit model. Textbook description of these methods is given by Train (2003). 


$$
\text { Substitution rate }=-\frac{\beta_{k}}{\beta_{s}} .
$$

These ratios represent marginal effects when the attributes are continuous and "values of level change", where the coefficients are referred to a specific level of a discrete attribute. When the attribute $x_{s}$ is expressed in monetary terms, this ratio represents the "implicit price" of the attribute, i.e. the amount of money that respondents are willing to pay to obtain more of the other attribute $\left(x_{k}\right) .{ }^{12}$ For computing the associated confidence intervals, the Krinsky-Robb technique or bootstrap methodologies are generally used.

\subsection{The empirical specifications}

We consider two empirical models basically. The first is the standard conditional logit specification where the probability of choosing a holiday is modeled simply as a function of the attributes considered. Individual heterogeneity is implicitly supposed to enter additively into individual utility functions, and is therefore constant across the different choice alternatives.

The second model considers individual effects entering in a multiplicative manner, accounted for by the introduction of interaction terms between attributes and tourist-specific socio-economic variables. Inclusion of interactions with choice-specific attributes allows to account for preference heterogeneity among respondents in the degree of attractiveness of alternative configurations of Rimini's offer. ${ }^{13}$

In particular, we verify whether foreign tourists feel more or less strongly about cultural policies, environmental protection, use of the beach late at night or pollution (noise, traffic, etc.). Moreover, we test for any differences in awareness of the better educated tourists with respect to cultural and environmental policies. Finally, we assess whether and how age classes (namely younger and older tourists) may influence preference for different holiday configurations.

All attribute levels are elaborated as dummy variables, with the exception of daily cost, which can be assigned four different values corresponding to four accommodation prices.

\section{Results and discussion}

\subsection{Main descriptive statistics}

The main characteristics of the sample of tourists on which the econometric analysis is based, are briefly described below. As shown in Table 2, the sample generally reflects the

12 This estimate typically relies on the assumption that the marginal utility of income is constant over the range of implicit income changes implied by the policy. This assumption is reasonable if the cost of a choice alternative represents a small amount with respect to individual income.

${ }^{13}$ Inclusion of interactions is also useful for addressing problems related to violations of the IIA hypothesis (Birol and Cox, 2007). 
tourist population in Rimini came out by the surveys of the National Institute of Statistics (ISTAT, 2005), and follows the established sample design.

Table 2: Socio-economic characteristics of the sample

\begin{tabular}{|c|c|c|c|c|c|c|c|}
\hline Gender & Freq. & $\%$ & $\begin{array}{l}\text { Sample } \\
\text { design }\end{array}$ & Age & Freq. & $\%$ & $\begin{array}{l}\text { Sample } \\
\text { design }\end{array}$ \\
\hline Male & 305 & 50.41 & 50.00 & $<30$ & 194 & 32.07 & \\
\hline Female & 300 & 49.59 & 50.00 & $30-44$ & 188 & 31.07 & \\
\hline \multirow[t]{6}{*}{ Total } & 605 & 100.00 & 100.00 & $45-59$ & 156 & 25.79 & \\
\hline & & & & $\geq 60$ & 67 & 11.07 & \\
\hline & & & & Total & 605 & 100.00 & \\
\hline & & & & Mean & 39.5 & & \\
\hline & & & & Min & 16 & & \\
\hline & & & & Max & 86 & & \\
\hline $\begin{array}{l}\text { Educational } \\
\text { Status }\end{array}$ & & & & $\begin{array}{l}\text { Place of } \\
\text { interview }\end{array}$ & & & \\
\hline \multirow{2}{*}{$\begin{array}{l}\text { No education/ } \\
\text { primary school }\end{array}$} & 42 & 6.94 & & Beach & 296 & 48.93 & 300 \\
\hline & & & & 2 star hotel & 15 & 2.48 & 0 \\
\hline Middle school & 170 & 28.10 & & 3 star hotel & 128 & 21.16 & 150 \\
\hline High school & 270 & 44.63 & & 4 star hotel & 12 & 1.98 & 0 \\
\hline University & & & & City centre & 52 & 8.60 & 50 \\
\hline $\begin{array}{l}\text { diploma, } \\
\text { degree or } \\
\text { Postgr. courses }\end{array}$ & 123 & 20.33 & & Pubs & 102 & 16.86 & 100 \\
\hline Total & 605 & 100.00 & & Total & 605 & 100.00 & 600 \\
\hline Income & & & & Nationality & & & \\
\hline Mean & 20,245 & & & Italians & 484 & 80.00 & 80.00 \\
\hline Median & 15,600 & & & Foreigners & 121 & 20.00 & 20.00 \\
\hline Income classes & & & & Total & 605 & 100.00 & 100.00 \\
\hline$<5000$ & 7 & 1.70 & & $\begin{array}{l}\text { Origin of } \\
\text { Italian tourists }\end{array}$ & Freq. & $\%$ & $\begin{array}{l}\text { ISTAT } \\
(2005)\end{array}$ \\
\hline $5000-7499$ & 28 & 6.80 & & Northern Italy & 337 & $69.63 \%$ & $64.80 \%$ \\
\hline $7500-9999$ & 29 & 7.04 & & Centre Italy & 85 & $17.56 \%$ & $18.46 \%$ \\
\hline $10000-12499$ & 76 & 18.45 & & $\begin{array}{l}\text { Southern Italy } \\
\text { and Islands }\end{array}$ & 62 & $12.81 \%$ & $16.83 \%$ \\
\hline $12500-14999$ & 45 & 10.92 & & Total & 484 & 100.00 & $100.00 \%$ \\
\hline 15000 - 19999 & 91 & 22.09 & & & & & \\
\hline 20000 - 24999 & 53 & 12.86 & & $\begin{array}{l}\text { Origin of } \\
\text { foreign tourists }\end{array}$ & Freq. & $\%$ & $\begin{array}{l}\text { ISTAT } \\
\text { (2005) }\end{array}$ \\
\hline $25000-39999$ & 46 & 11.17 & & Western Europe & 95 & 79.17 & $55.5 \%$ \\
\hline$\geq 40000$ & 37 & 8.98 & & Eastern Europe & 19 & 15.83 & $29.42 \%$ \\
\hline No of answers & 412 & 100.00 & & Other countries & 6 & $5.00 \%$ & $15.08 \%$ \\
\hline Response rate & $68.10 \%$ & & & Total & 120 & $100.00 \%$ & $100.00 \%$ \\
\hline
\end{tabular}

Males and females are equally represented in the sample, the average age of respondents being 40 . The elderly and retired are likely to be underrepresented as they tend to take 
holidays in the off-peak season (May, June or September not covered by our survey), enjoying cooler weather and cheaper rates. About $65 \%$ of respondents received at least a high school education, 20.3\% a university degree. As for geographical origin, the majority of Italian respondents $(69.6 \%)$ are from Northern regions, while out of the $20 \%$ foreign tourists, $79.1 \%$ live in Western European countries, Germany being the most represented. We also gathered information on individual income, though only $68 \%$ of respondents answered this question. Reported average annual income is 20,245 Euros, median income 15,600 Euros.

Table 3 summarizes information gathered on the kind of holiday taken by respondents. Most tourists prefer traditional full board hotel accommodation $(66.2 \%)$ and the great majority organize their own holiday (82.8\%). Moreover, only $24 \%$ of respondents use Internet to retrieve information about activities and services offered at the destination or to book accommodation, travel and services. These findings indicate that visitors to Rimini are fairly experienced tourists. The average stated daily expenditure in the high season is 76 Euros, which may seem a relatively small amount by Italian standards, but is consistent with national-level estimates.

Table 3: Characteristics of the actual tourist experience

\begin{tabular}{|c|c|c|c|c|c|}
\hline Use of Internet & Freq. & $\%$ & $\begin{array}{l}\text { All inclusive } \\
\text { package }\end{array}$ & Freq. & $\%$ \\
\hline Yes & 147 & 24.30 & Yes & 104 & 17.19 \\
\hline No & 458 & 75.70 & No & 501 & 82.81 \\
\hline Total & 605 & 100.00 & Total & 605 & 100.00 \\
\hline \multicolumn{3}{|l|}{$\begin{array}{l}\text { Accommodation } \\
\text { type }\end{array}$} & \multicolumn{3}{|l|}{ Transport mode } \\
\hline Overnight stays & 18 & 3.42 & Car & 425 & 70.25 \\
\hline $\mathrm{B} \& \mathrm{~B}$ & 70 & 13.28 & Train & 101 & 16.69 \\
\hline Half board & 90 & 17.08 & Plane & 23 & 3.80 \\
\hline \multirow{2}{*}{ Full board } & 349 & 66.22 & Coach & 54 & 8.93 \\
\hline & & & Camper & 2 & 0.33 \\
\hline Total & 527 & 100.00 & Total & 605 & 100.00 \\
\hline \multicolumn{6}{|l|}{ Daily cost } \\
\hline Mean & 76 & & & & \\
\hline Min & 15 & & & & \\
\hline Max & 350 & & & & \\
\hline $\begin{array}{l}\text { Daily Expenditure } \\
\text { classes (Euros) }\end{array}$ & & & Low-cost flight & & \\
\hline$<40$ & 17 & 2.81 & Yes & 10 & 43.48 \\
\hline $40-54$ & 114 & 18.84 & No & 13 & 56.52 \\
\hline $55-69$ & 128 & 21.16 & & & \\
\hline $70-84$ & 185 & 30.58 & & & \\
\hline $85-99$ & 39 & 6.45 & & & \\
\hline $100-124$ & 86 & 14.21 & & & \\
\hline$\geq 125$ & 36 & 5.95 & & & \\
\hline Total answers & 605 & 100.00 & Total & 23 & 100.00 \\
\hline
\end{tabular}


Respondents were asked to rank (high, medium, low) the importance of each of the six attributes in determining their choices in the CEs. Importance levels were assigned scores of 100, 75 and 55. The main results are summarized in Figure 2 by nationality and holiday type. The average value for each attribute is reported in the graph ${ }^{14}$ which shows a clear difference in the importance assigned by Italian and foreign tourists to additional cultural services. By contrast, prices do not seem to be a crucial variable in the holiday decision making process, in particular for weekend tourists, in spite of the fierce competition among local tourism service suppliers. Similarly, neither overcrowding nor environmental sustainability are explicitly recognized as choice determinants.

\section{Figure 2: Stated importance of attributes in holiday decision making process}

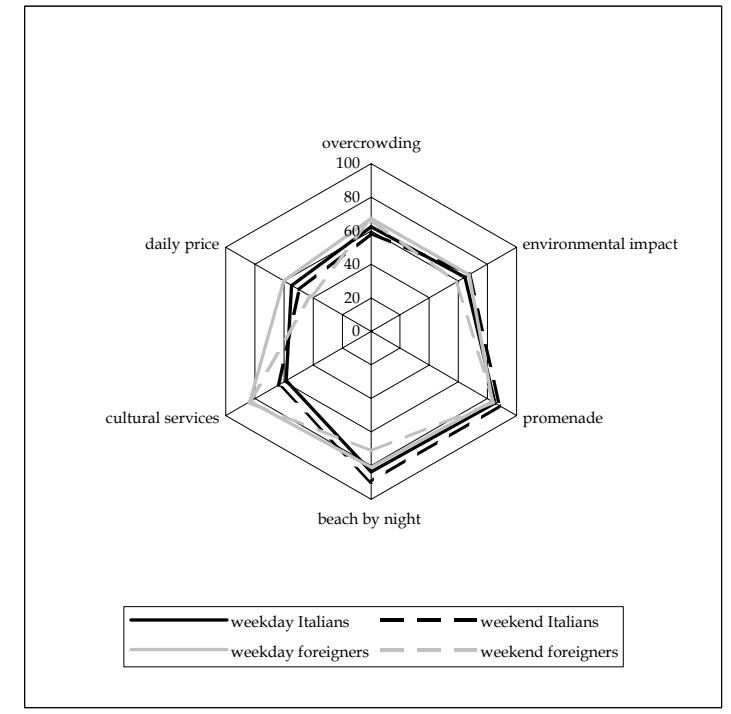

\subsection{Conditional logit model results}

The estimates obtained applying the basic conditional logit model to the sample as a whole are shown on the left-hand-side of Table 4. As can be seen, respondents appear to have considered all six attributes in choosing among the proposed alternatives. All attribute levels are statistically significant, with the exception of the high temporary impact of beach

${ }^{14}$ For a more detailed analysis see Scorcu and Vici (2006). 
facilities, possibly because these effects were not perceived to differ substantially from a high permanent impact. ${ }^{15}$

An intuitive way of interpreting the estimated parameters is to compute the relative weights of the various attributes and levels, i.e. the rate at which respondents are willing to trade-off one attribute for another. This is shown in the second column of Table 4 where the coefficients are normalized with respect to the value of the seafront pedestrianisation attribute. The risk of overcrowding is thus shown to be of some, though not substantial, importance ( 0.52 compared to the positive effect of the promenade), whereas the added value of introducing temporary beach facilities, dismantled in low season, would be about one third (0.35). The impact of beach facilities on the environment was perceived as a minor problem, no significant improvements to be gained from a "beach only" scenario, which reflects the "typical" image of tourism in Rimini. Indeed, only one new feature scored higher than pedestrianization of the seafront, namely the possibility of "late night opening". This is a clear indication that the Rimini seafront is diversifying its offer, the role of the traditional sun, sea and sand holiday becoming less significant.

For local authorities, pedestrianisation and late-night opening of the seafront may be fairly difficult to implement in the short run. Therefore "simpler" policies like enjoyment of local monuments and the currently undervisited city and ethnic museums produce interesting positive effects.

The right-hand-side of Table 4 shows the conditional logit model estimation results with interactions for different age groups, nationality and educational status. In order to keep the size of the table manageable we have omitted from the final estimation those interactions which did not attain at least a 10\% significance level. Parameter estimates are however unaffected by their exclusion. The summary statistics indicate a better goodness-of-fit for this model. The following important aspects concerning respondents' preferences have been identified.

First, only one supply configuration seems to clearly differentiate foreign from Italian tourists, i.e. the cultural offer in the town which combines seaside holidays with visits to monuments and the city museum.

Second, better educated respondents are more environmentally concerned. On the contrary, and quite surprisingly, the availability of cultural attractions does not significantly affect choices by this group of people.

Third, a strong distinction emerges between the young (less than 30) and older (over 60) respondents concerning late-night opening of the beach. Though, on the whole, all respondents positively evaluate this improvement in the tourism offer, the younger tourists ranked it as twice as important. This was to be expected, as young people are more likely to

15 Tourists staying in Rimini during the summer season were unable to appreciate the difference between the two alternatives. However, this could be an indirect indication of the relatively low importance given to environmental issues. 
frequent late night venues such as discos and pubs, and late-night opening the beach could probably increase the nightlife offer providing new venues for the organization of events and shows.

Table 4: Conditional logit model estimates

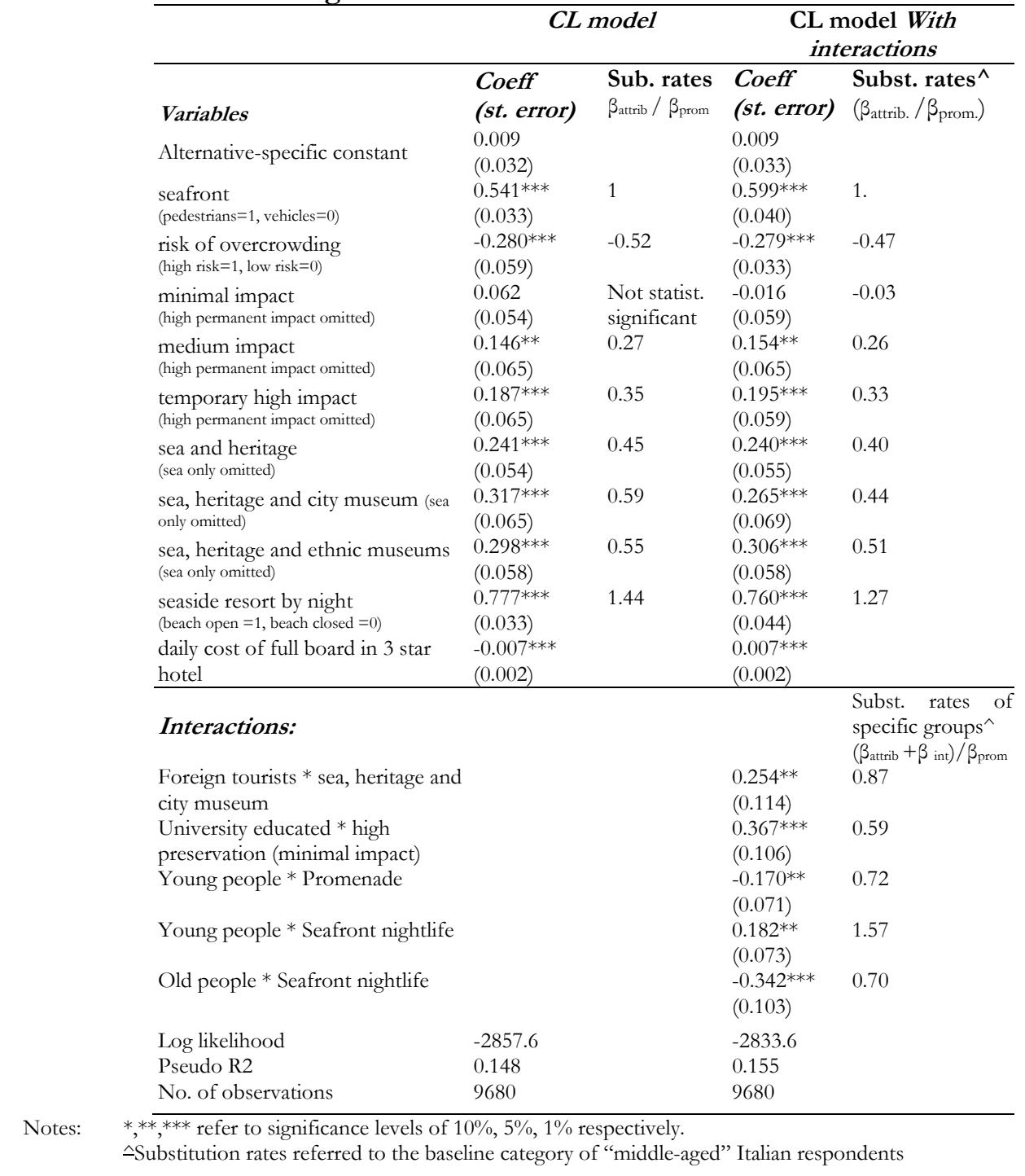


Fourth, pedestrianization of the main seafront has an overall positive effect on tourist choice probabilities, though the effect of this attribute is significantly less for young people ($28 \%$ with respect to the baseline sample of middle-aged Italian tourists).

On the whole, we can conclude that the main drivers influencing tourist choice are always the traffic-free promenade and the late-night opening of the beach, though in both cases there may be considerable generational differences.

Both regressions shown in Table 4 yielded a negative statistically significant coefficient for the cost of accommodation, indicating that respondents have not neglected this fundamental aspect of the holiday. However, in order to draw reliable conclusions about the concrete additional willingness to pay of tourists actually visiting Rimini, not only is the statistical significance important but also the absolute size of the detected effect. This is confirmed by examining the estimated marginal prices for each attribute level shown in Table 5. Implicit price estimates are made on the ceteris paribus assumption, namely for an increase in the attribute of interest, all else being constant. ${ }^{16}$

\section{Table 5: Implicit price estimates using the basic CL model}

\begin{tabular}{lcc} 
& \multicolumn{2}{c}{ CL model without interactions } \\
\hline Level changes & Implicit price & Standard error \\
\hline $\begin{array}{l}\text { Pedestrian seafront } \\
\text { Risk of overcrowding }\end{array}$ & 79.8 & $50.8-175.6$ \\
& -41.4 & $-92.7--25.0$ \\
$\begin{array}{l}\text { Variation in beach impact from high } \\
\text { permanent to minimal impact }\end{array}$ & Not stat. sign. & Not stat sign. \\
$\begin{array}{l}\text { Variation in beach impact from high } \\
\text { permanent to medium impact }\end{array}$ & 21.5 & $2.3-57.0$ \\
$\begin{array}{l}\text { Variation in beach impact from high } \\
\text { permanent to high temporary impact }\end{array}$ & 27.6 & $9.8-65.9$ \\
$\begin{array}{l}\text { Variation in tourism product from sea only } \\
\text { to sea and monuments }\end{array}$ & 35.6 & $17.1-84.6$ \\
$\begin{array}{l}\text { Variation in tourism product from sea only } \\
\text { to sea, monuments and traditional museums }\end{array}$ & 46.9 & $17.4-84.3$ \\
$\begin{array}{l}\text { Variation in tourism product from sea only } \\
\text { to sea, monuments and ethnic museums }\end{array}$ & 44.0 & $23.7-107.4$ \\
\begin{tabular}{l} 
Late night opening of the beach. \\
\hline
\end{tabular} & 114.8 & $73.5-250.1$ \\
\hline
\end{tabular}

16 Two considerations should be recalled in calculating implicit prices: firstly, we are dealing with discrete level variations (and not marginal). Secondly, these estimates are based on the assumption that the marginal utility of income is constant, an assumption reliable only when small level changes are considered (involving a minor proportion of total personal income). 
As can be observed, most of these values are certainly abnormal (up to 114 Euros for accessing the beach at night!), compared to actual accommodation costs in standard threestar hotels. Although in the experiment respondents prove sensitive to price differences, the weight assigned to the price attribute appears to be very low. This certainly weakens the applicability of WTP measures for a direct comparison between the economic benefits accruing by a specific change of the current tourism offer and the costs necessitated to carry out such transformations.

\subsection{Policy simulation}

Using the conditional logit estimates obtained for the choice experiment, it is possible to predict the purchase probability of a given tourism product. By choosing suitable holiday attractions that tourists are most likely to visit, these simulations can provide a useful and intuitive tool for policy makers and private tourism businesses for designing products specifically tailored to tourists' needs.

This kind of simulation is made possible by the IIA property of the conditional logit model. In fact, provided that IIA holds, simulations are not constrained to the number of alternatives considered in the choice experiments. To make operational this point, consider the simulation with five alternative hypothetical holidays reported in Table 6.

The different scenarios comprise different combinations of the five qualitative attributes, keeping the cost of accommodation constant across the alternatives. The labels indicate the different potential positioning of each scenario in the market: status quo, beach only, environmentally friendly resort, Rimini by night and intensive Rimini.

It clearly emerges that the town's current tourism offer (the "status quo" scenario) far from effectively satisfies visitors, whereas the first choice, for the whole sample and the different sub-samples considered in the present simulation, is the "beach only" alternative.

This exercise provides indications for targeted policies when examining the second best holiday alternative, which differs across the subgroups considered. Foreign tourists and over 60-year olds appear to appreciate the "environmentally friendly resort", while younger tourists are little interested in this kind of resort, preferring the "tourism-intense Rimini" scenario. Since public and private operators are in favour of the latter scenario, then they will clearly have to provide services for young Italian tourists and tour operators. 
Table 6: Simulation of market share in a case of 5 choice alternatives (same accommodation price)

\begin{tabular}{|c|c|c|c|c|c|}
\hline Attributes & $\begin{array}{l}\text { Status } \\
\text { quo }\end{array}$ & $\begin{array}{l}\text { Beach } \\
\text { only }\end{array}$ & $\begin{array}{l}\text { Environment } \\
\text { ally friendly } \\
\text { resort }\end{array}$ & $\begin{array}{l}\text { Rimini } \\
\text { by night }\end{array}$ & $\begin{array}{l}\text { Tourism- } \\
\text { intense } \\
\text { Rimini }\end{array}$ \\
\hline Seafront & $\begin{array}{l}\text { Vehicle } \\
\text { access }\end{array}$ & Pedestrian & Pedestrian & $\begin{array}{l}\text { Vehicle } \\
\text { access }\end{array}$ & Vehicle access \\
\hline Overcrowding & high risk & low risk & low risk & high risk & high risk \\
\hline $\begin{array}{l}\text { Environmental } \\
\text { impact }\end{array}$ & high & high & minimal & high & $\begin{array}{l}\text { temporary } \\
\text { high }\end{array}$ \\
\hline Holiday type & sea only & sea only & $\begin{array}{l}\text { sea, } \\
\text { monuments, } \\
\text { city museum }\end{array}$ & $\begin{array}{l}\text { sea \& } \\
\text { mo- } \\
\text { numents }\end{array}$ & $\begin{array}{l}\text { sea, monu- } \\
\text { ments, ethnic } \\
\text { museums }\end{array}$ \\
\hline $\begin{array}{l}\text { Late night beach } \\
\text { access }\end{array}$ & No & Yes & No & Yes & Yes \\
\hline \multicolumn{6}{|l|}{ Choice probabilities } \\
\hline $\begin{array}{l}\text { Whole sample } \\
\text { (CL Model without inter) }\end{array}$ & $6.4 \%$ & $31.8 \%$ & $21.3 \%$ & $17.8 \%$ & $22.7 \%$ \\
\hline $\begin{array}{l}\text { Foreign tourists: } 30-60 \\
\text { (CL Model with inter..) }\end{array}$ & $6.1 \%$ & $31.4 \%$ & $24.3 \%$ & $16.6 \%$ & $21.6 \%$ \\
\hline $\begin{array}{l}\text { Italian tourists: } 30-60 \\
\text { (CL Model with inter.) }\end{array}$ & $6.5 \%$ & $33.2 \%$ & $20.0 \%$ & $17.6 \%$ & $22.8 \%$ \\
\hline $\begin{array}{l}\text { Italian tourists: }>60 \\
\text { (CL Model with inter.) }\end{array}$ & $8.2 \%$ & $30.0 \%$ & $25.4 \%$ & $15.8 \%$ & $20.6 \%$ \\
\hline $\begin{array}{l}\text { Italian tourists: }<30 \\
\text { (CL Model with inter.) }\end{array}$ & $6.1 \%$ & $31.9 \%$ & $16.0 \%$ & $20.0 \%$ & $26.0 \%$ \\
\hline
\end{tabular}

\section{Conclusions}

This study has illustrated how discrete choice experiments can be useful for the economic analysis of tourism, by eliciting tourist preferences, priorities and willingness to pay for a tourism product, seen as a composite good having several constituent characteristics.

This approach differs from many other techniques used to explore what a tourist destination has to offer. The main advantage consists in a detailed study of tourism demand, obtaining feedback for enhancing the local tourism product. Using this information, the development of a tourist area can be based on tourists' elicited preferences rather than on local policymaker beliefs, whose perception of tourist needs might not match that of important market niches (e.g., the perception of younger tourists of the creation of a pedestrianised seafront of the town with respect to the "enthusiastic" reaction to late-night opening of the beach. 
The study was carried out on a sample of about 600 tourists, interviewed during their summer holidays in Rimini, Italy in 2005. The questionnaire was administered to a sample largely representative of an experienced tourists. The characteristics considered in our choice experiments could not exhaustively represent the current and potential make up of Rimini's tourist offer as a whole. Nonetheless, the chosen attributes represent policy tools on which local policymakers are in principle able to take action. In fact, Rimini is a mass tourist destination, confronted with the problems typical of mature destinations ${ }^{17}$ and therefore needs to identify interventions for rejuvenating its tourism product.

The main result that emerges from the analysis is that the current offer does not satisfy the demand of experienced tourists visiting Rimini. Another clear policy recommendation that strongly emerges is the minor importance assigned to environmental sustainability. Quite likely, the overall quality of the north-western Adriatic coast is now such that tourists visiting the area are not actually seeking environmentally friendly tourism. Also enhancing the cultural offer would have a limited effect, except for the minority of foreign visitors. By contrast, both Italian and foreign tourists would appreciate a more intensive use of natural resources, with the possibility of late-night opening of the beach of seafront amenities and facilities. In turn, this requires additional recreational activities so as to diversify late-night entertainment. A key issue would arise in the event local authorities were limited to just one intervention. Younger tourists would primarily appreciate access to the beach. By contrast, the over-60s would largely prefer the creation of a traffic free seafront.

We cannot however conceal our mixed conclusions as to the suitability of CEs for evaluating large-scale interventions in a tourist destination. The method has not proved a satisfactory research tool for obtaining reliable welfare measures for use in a systematic costbenefit analysis, whereas it performed well in assessing the relative appeal of the different projects.

This study did prove useful for identifying those factors that could better satisfy current tourist demand. Taking advantage of the main results, also potential markets might be positively affected, provided that present and potential tourist preferences do not differ substantially.

${ }^{17}$ The obvious reference for this kind of problem is the seminal article by Butler (1980). 


\section{References}

Adamowicz, W., Boxall, P., Williams, M. and Louviere, M. (1998) Stated preference approaches for measuring passive use values: choice experiments and contingent valuation, American Journal of Agricultural Economics, 80, pp. 64-75.

Alberini A., Longo A., Tonin S., Trombetta F. and Turvani M. (2005a) The role of liability, regulation and economic incentives in brownfield remediation and redevelopment: evidence from surveys of developers, Regional Science and Urban Economics, 35, pp. 327351.

Alberini, A., Zanatta, V., and Rosato, P. (2005b) Combining actual and contingent behaviour to estimate the value of sport fishing in the lagoon of Venice, FEEM Working Paper, n. 44.05 .

Apostolakis, A. (2003) The Convergence Process in Heritage Tourism, Annals of Tourism Research, 30, pp. 795-812.

Bennett, J., and Blamey, R. (Eds.) (2001), The choice modeling approach to environmental valuation (Cheltenham, Edward Elgar).

Birol, Ekin and Cox, Victoria (2007) Using choice experiments to design wetland management programmes: The case of Severn Estuary Wetland, UK, Journal of Environmental Planning and Management, 50, pp. 363-380

Brau, R., and Cao, D. (2006) Uncovering the macrostructure of tourists' preferences. A choice experiment analysis of tourism demand to Sardinia, FEEM Working Paper, n. 33.06.

Breffle, W., and Morey, E. (2000) Investigating Preference Heterogeneity in a Repeated Discrete-Choice Recreation Demand Model of Atlantic Salmon Fishing, Marine Resource Economics, 15, pp. 1-20.

Butler R.W. (1980) The concept of a tourism area cycle of evolution: implications for management of resources, Canadian Geographer, 24, 5-12.

Carson, R. (2000) Contingent Valuation: a User's Guide, Environmental Sciences and Technology, 34(8), pp. 1413-1418.

Crouch, G.I., Oppewal, H., Huybers, T., Dolnicar, S., Louviere, J.J. and Devinney, T. (2007) Discretionary Expenditure and Tourism Consumption: Insights from a Choice Experiment, Journal of Travel Research, 45(3), pp. 247-258.

Crouch, G.I. and Louviere, J.J. (2004) The Determinants of Convention Site Selection: A Logistic Choice Model from Experimental Data, Journal of Travel Research, 43(2), pp. 118130.

Figini, P., Castellani, M. and Vici, L. (2007) Estimating Tourist Externalities on Residents: a Choice Modeling Approach to the Case of Rimini, FEEM Working Paper, n. 76.07.

Hensher, D., Rose, J. and Greene, W. (2005) Applied Choice Analysis: a Primer (Cambridge, Cambridge University Press). 
Huybers, T. (2005) Destination choice modeling: what's in a name?, Tourism Economics, 11(3), pp. 329-350.

Huybers, T., and Bennett, J. (2000) Impact of the environment on holiday destination choices of prospective UK tourists: implications for Tropical North Queensland, Tourism Economics, 6, pp. 21-46.

ISTAT (2005) Il turismo nel 2004, Statistiche in breve, Roma.

Lancaster, K. (1966) A New Approach to Consumer Theory, Journal of Political Economy, 74(2), pp. 132-157.

Lancaster, K. (1971) Consumer Demand - A New Approach (New York, Columbia University Press).

Louvière, J.J., Hensher, D.A. and Swait, J.D. (2000) Stated choice methods, (Cambridge, Cambridge University Press).

McFadden, D. (1984) Econometric analysis of qualitative response models, in Z. Griliches and M.D. Intriligator (Eds.), Handbook of Econometrics II (Amsterdam, Elsevier Science).

McFadden, D. (1974) Conditional logit analysis of qualitative choice behaviour, in P. Zarembka (Ed.), Frontiers in econometrics (New York, Academic Press).

Mogas, J., Riera, P. and Bennett, J. (2006) A comparison of contingent valuation and choice modeling with second-order interactions, Journal of Forest Economics, 12, pp. 5-30.

Morey, E., Rossmann, K.G., Chestnut, L.G. and Ragland, S. (2002) Valuing Reduced Acid Deposition Injuries to Cultural Resources: Marble Monuments in Washington DC, in S. Navrud and R.C. Ready (Eds.), Valuing Cultural Heritage (Cheltenham, Edward Elgar).

Morley, C. (1995) Tourism demand: characteristics, segmentation and aggregation, Tourism Economics, 1, pp. 315-328.

Papathodorou, A. (2001) Why people travel to different places, Annals of Tourism Research, 28(1), pp. 164-179.

Scorcu, A.E. and Vici, L. (2006) Il turismo balneare a Rimini: scenario attuale e possibili evoluzioni nelle preferenze dei turisti, University of Bologna (centre of Rimini) Working Paper, $\mathrm{n}$. $3 / 2006$,

Thurstone, L.L. (1927) A Law of Comparative Judgment, Psychological Review, 34, pp. 273-286.

Train, K.E. (2003) Discrete choice methods with simulation, (Cambridge, Cambridge University Press). 